\section{Foetus into Man. Physical Growth from Conception to Maturity}

By J. M. Tanner. (Pp. 250; Figures + Tables. $£ 4 \cdot 50$.) London: Open Books. 1978.

This book gives an excellent account of current knowledge of the control of human growth from conception to the end of the adolescent growth spurt. One important principle derived from experimental observation is that a cessation of growth at the time of grovvth by cell division has permanent sequelae. Regrowth starts at a rate appropriate to chronological age. In contrast, a cessation at the time of growth by cell enlargement has no permanent aftereffects and 'catch-up' is usually complete.

The section on growth before birth includes the recent information obtained by ultrasonography. In accordance with the principle stated above, retardation of growth in the first half of pregnancy tends to be associated with permanent small size and mental retardation. Later retardation, due to maternal malnutrition or small maternal size, tends to be followed by full catch-up growth if postnatal conditions are favourable.

The section on the development of sexual dimorphism incorporates recent developments in endocrinology. Particularly striking is the narrow sensitive period in the rat (just 5 days after birth) in which the hypothalamus is switched to the male pattern of non-cyclical activity by testosterone. It is not yet known whether there is a corresponding similar sensitive period (this would be the 12th to 14 th weeks after conception) in man. Again, in the rat there is evidence of similar critical differentiation of a centre controlling mating behaviour. The account of the endocrine control of growth includes the recent advances in knowledge of the regulation of secretion of pituitary growth hormone which in man controls the production of somatomedin.

The section on genetic and environmental influences over the control of adult stature is wellbalanced, though the author does attempt an estimation of heritability. Chinese and Japanese children, even under optimal conditions, are smaller than north Europeans, and are even shorter when full-grown because of earlier maturity (menarche is about 6 months earlier). Negroes, and, even more, Australian aboriginals, have relatively greater leg length in relation to sitting height than Chinese and Japanese, while Europeans are intermediate in this respect. These are genetic differences. It is noteworthy that differences in Sweden in full adult height by social class of parents appear to have disappeared. Further, the secular increase in full adult stature appears to be coming to an end in northern Europe. These were presumably environmental effects. Professor Tanner does not discuss the origin or the duration of the secular change, but it is the reviewer's belief that much of it represents a recovery from the stunting of children associated with the chronic malnutrition and long hours of work of young children at the time of the industrial revolution. Professor Tanner gives an equally well-balanced account of the controversial topic of the effects of malnutrition on brain growth.

A long chapter on the Standards of Normal Growth reflects the expertise and extensive experience of the author and his colleagues in longitudinal growth studies, including a convenient method of allowing for parental height in estimating a child's expected position in relation to his peers. Here, perhaps, the author might have included an explanation of the genetic reasons why individual children in a family tend to vary widely round the midparental mean, and why a child's height at age 10 (even after correcting for skeletal age) is only of limited value in predicting his full adult height.

The books ends with an admirably complete set of references.

C. O. Carter

\section{Introduction to Biological Scanning Electron Microscopy}

By M. A. Hayat. (Pp. xviii $+323 ; 54$ Figures + 7 Tables. $£ 9 \cdot 25, \$ 14 \cdot 95$.) Baltimore, London, Tokyo: University Park Press. 1978.

Professor Hayat's book is designed as a basic text in the principles and practice of biological scanning electron microscopy. In such a book, one of the formidable problems is to draw a balance between brevity and clarity. If the volume is to achieve its objective it must enable the inexperienced experimenter to attain at least an encouraging level of success. The first part of the book deals with instrumentation and supplies an adequate background to the history and principles of the method. The author sensibly avoids too much in the way of theoretical 
physics which can be daunting even to those familiar with the field of transmission electron microscopy. However, enough information is given to make comprehension of the machine's mode of functioning, and thus interpretation of the results, not too difficult.

It is in the section of the book dealing with specimen preparation that the limitations of an introductory text become more apparent. A laboratory worker moving into a new field is inevitably confronted with a very specific problem or problems, and a book of this nature cannot deal in a sufficiently detailed manner with each of these. Professor Hayat gets round this problem by describing methods in broad detail and by providing an extensive and commendably up-to-date reference list for dealing with specific tissues and cell types. This does, of course, make the book of limited use in practical terms, and for the worker about to embark on a scanning EM project the multivolume treatise edited by Professor Hayat is probably a more useful series. This current book would, however, provide useful information for people who wish to decide whether the method would be appropriate to a specific problem, though a bigger selection of micrographs would enable the uninitiated to judge more realistically the kind of information which the available methodology could supply.

Patricia R. ManN

The Hemoglobinopathies. Techniques of Identification

Clinical and Biochemical Analysis, Vol. 6. By Titus H. J. Huisman and J. H. P. Jonxis. (Pp. v + 449; Figures + Tables. SFr. 140.) New York: Marcel Dekker. 1977.

This book is, in effect, a sequel to the two editions of the 'Laboratory Manual' written by the same authors and first published in 1958 by Blackwell Scientific Publications. The real value of the new book still lies in the very detailed sections on laboratory techniques and their application in the diagnosis and study of the haemoglobinopathies. It is fortunate that these sections make up the bulk of the book, because the early chapters on the clinical and population aspects, and the final chapters on the normal and abnormal haemoglobins, are not of the same high standard. These additional chapters do not make the volume 'the only comprehensive book on the topic' as the publishers claim, and indeed this claim may mislead potential buyers.

This book remains a laboratory manual of haemoglobin techniques and a very good one at that. Viewed in this way the book is an up-to-date, comprehensive guide for the haematologist and fins colleagues concerned with the laboratory aspects ff screening programmes and the identification of haemoglobinopathies. The book would be particelilarly valuable to anyone setting up or expandiag such laboratory facilities. ڤ્

When I say that the core of the book is a laboratory manual, I mean that sufficiently detailed instructions are given to allow a competent technician to set $\overrightarrow{u p}$ and carry out the analysis described with reliable results. In the chapters on Methods (which make half the book) a standard format is adopted to describe each technique, with a full equipment list and precise details of the reagents required before the procedure itself is described. Comments concernigुg the methodology itself follow immediately, whileoa wide consideration of the applications of the techniques constitutes a separate chapter, an arrangement that works well.

There is an excellent section on the new quantittive microchromatography methods for $\mathrm{Hb} \mathrm{A_{2 }}$, and $F$ (in the absence of $A$ ) which use columns poured into ordinary Pasteur pipettes. The quantification off $\mathrm{Hb} \mathrm{A}_{2}$, using either Tris-Hcl developer or glycine$\mathrm{KCN}$ as a developer (which allows $\mathrm{Hb} \mathrm{A}_{2}$ measuzment without interference from $\mathrm{Hb} \mathrm{S}$ in the samp (r) is considered in detail, and the discrimination between $\mathrm{Hb} \mathrm{A}_{2}$ levels in 5352 normal adults and 306 $\beta$-thalassaemia traits using these techniques as shown to be just as good as the best of the longgr established routine methods. The value of these microchromatography methods is further shown th the chapter on applications, where not only are the results from Dr Huisman's own laboratory Georgia discussed, but also those from a very large survey in Yugoslavia (communicated by Dr G. B. Efremov) and a large study in Ghana (communi cated by Ruth $\mathrm{N}$. Wrightstone).

The discussion of the latter, conducted in 'extreme conditions' is particularly welcome, for one shougd not forget that what may appear extreme to somexis typical for many laboratories in those countris where the haemoglobinopathies are commono; though standards are improving, many people are still obliged to work with inadequate air conditionit in hot and humid climates. It is encouraging $f$ people tackling these problems to have an authoritgtive book on techniques which is prepared to admit to difficulties caused by mould growing in the buffe्ष़!

The last chapter gives a necessarily brief accouft of the structure, function, and synthesis of the normal haemoglobins and the inevitable list Q̊f abnormal haemoglobins (which, with the addendu周, covers the literature up to March 1977). 